\title{
The Impact of Social Exchange Relationship Perception on Employees' Adaptive Performance: The Mediating Role of Emotional Commitment
}

\author{
Lan-yun WANG \\ School of Business \\ Tianjin University of Finance and Economics \\ Tianjin China \\ wlyn2007@163.com
}

\author{
Dan SONG* \\ School of Business \\ Tianjin University of Finance and Economics \\ Tianjin China \\ 1139915329@qq.com
}

\author{
Dan-dan HUO \\ School of Business \\ Tianjin University of Finance and Economics \\ Tianjin China
}

\begin{abstract}
The purpose of this study is to explore the relationship between employees' social exchange relationship perception and adaptive performance. Based on the social exchange theory and performance management theory, this study investigated 258 employees in Beijing-Tianjin-Hebei Region by questionnaires, and then do data processing by regression analysis. Results show that social exchange relationship perception has a significant positive predictive effect on adaptive performance and the same for its three dimensions. Also, emotional commitment plays a mediating role in social exchange relationship perception and adaptive performance. This study enriches the mechanism exploring about employee adaptive performance from the perspective of social exchange relations, and may have some value for corporate to improve performance management.
\end{abstract}

Keywords—social exchange; relationship perception; emotional commitment; adaptive performance

\section{INTRODUCTION}

The increasingly complex and ever-changing external competitive environment puts higher demands on the company's adaptability and innovation ability. For most industries, the differentiation of technology and products is no longer a key competitive advantage, only those that can adapt quickly to change and create change will be sustainable. The individual's adaptability, behavioral flexibility and accordingly the organizational learning and innovation performance are important sources for the company to cope with the external environment transformation. Therefore, individual adaptability has become a hot spot for enterprises and scholars in recent years [1]. As an important management mechanism, performance management has occupied an important position in human management practice and corporate strategic management, and it becomes a key success factor for organizational. However, for a long time, performance management theory research pay much attention to task

This research was supported by Tianjin Philosophy and Social Sciences Planning Key Project "Impact of Performance Appraisal Perception on Innovative Behavior of Knowledge Workers" (No. TJGL16-007). performance; and in practice, the reward and recognition system also focuses on the completion of tasks and goals. The problem is therefore bring a short-term orientation for both individual and organizational performance management, emphasizes the contribution of employees to the organization in the static environment, and pays insufficient attention to the individual's ability to adapt to the dynamic changes of the organization and the environment. In an increasingly uncertain environment, past performance measurement approaches cannot cover all factors that nowadays employees contribute to organizational effectiveness. In recent years, changes in work and organizational nature are challenging traditional perceptions of individual performance [2]. Practice has proved that in a complex and ever-changing environment, organizations not only need to pay attention to task performance of employees who clearly describe those organizations, but also pay attention to the contribution of employees in adapting to environmental changes and challenges. Therefore, the concept of adaptive performance has emerged in this area [3].

At the individual level, adaptive performance is seen as the extent to which employees demonstrate behavioral changes as the work itself or the work environment change [4]. Pulakos et al. further summarized the eight-dimensional model of adaptive performance, they are as follows: ability to handle work stress in dealing with emergency and crisis situations, ability to solve problems creatively, ability to handle uncertain working situations, ability to learn about work tasks, skills and processes, ability to interpersonal adaptability, ability to cultural adaptability, and ability to environmental adaptability [5]. Johnson believes that effectively addressing unpredictable and changing work situations, learning new tasks, skills, and processes belong to the content of adaptive performance, which is different from task performance and organizational citizenship behavior. Griffin [6] et al. further clarified the meaning of adaptability, and divided adaptability into three 
different behavior types: proactive adaptive behavior, reactive adaptive behavior and tolerant adaptive behavior. Proactive adaptive behavior is an action in which an individual has a positive impact on changes in the environment; reactive adaptive behavior is an act of changing oneself to better adapt to the new environment; tolerant adaptive behavior means that behaviors continue to work when environment is changing, or when proactive and reactive behavior may not be appropriate. In short, at the individual level, adaptive performance can be seen as the result of individual self-management and learning new knowledge and skills. However, theoretical research on how to improve adaptive performance is currently limited. Adaptive performance as the employee's expected employee behavior and results, how social exchange relationship perception affects adaptive performance is currently rarely studied [7].

The employee-organization relationship is actually an exchange relationship. Organizations induce employees to contribute to its development with material or emotional incentives, meanwhile employees obtain material and spiritual needs for survival and development from organization[8]. Blau believes that only social exchanges can bring individuals a sense of obligation, gratitude and trust that are essential for an organization to accomplish its goals. Adaptive behavior often exceeds the requirements of job responsibilities in job description. Therefore, whether individuals are willing to cope with changes in work content or work environment to learn new skills, new processes, and whether they exhibit adaptive behavior et al. have not got clear conclusion.

Therefore, from the perspective of employee exchange relationship perception, this paper explores the impact of employee social exchange relationship perception on adaptive performance. At the same time, it also tests the impact of economic exchange perception for further comparing; Furthermore, emotional commitment is chosen as a mediating variable for exploring the path which social exchange relationship perception impact on adaptive performance. This study may enrich the relevant theoretical research on employee exchange relationship perception and adaptive performance, and help organization to improve their performance management.

\section{THEORETICAL ANALYSIS AND HYPOTHESIS}

\section{A. Relationship between social exchange relationship perception and adaptive performance}

Some scholars have conducted research on employeeorganizational relationships and have drawn some useful conclusions. Jia \& Shaw (2014) argues that positive employeeorganization relationships have a significant positive impact on team innovation; Shore et al. found that employees perceive social exchange relationships and economic exchange relationships in organizational commitment, job performance, and organizational citizenship behavior (OCB) The conduction between the two; Tsui et al. confirmed that social exchange relationship perception has a significant positive effect on employee's task performance and organizational citizenship behavior[9]; Zhu Yanhan also found that social exchange relationship perception for employees' roles and roles within the role of employees External behavior also has a positive impact[10].

Adaptive performance have three dimensions: emergent, relationship and learning adaptive performance[11].Adaptive performance includes certain organizational citizenship behaviors and extra-role behaviors or innovative behaviors. When employees perceive there are not only economic exchange relationships but also social exchange relationship with the organization, they will do more for return. Therefore, this paper proposes the following hypothesis:

H1a: There is a positive correlation between social exchange relationship perception and strain surface adaptive performance.

H1b: There is a positive correlation between social exchange relationship perception and relational adaptive performance.

H1c: There is a positive correlation between social exchange relationship perception and learning face adaptive performance.

\section{B. Relationship between economic exchange relationship perception and adaptive performance}

Material exchange is the basis for the establishment of long-term exchanges between employees and organizations. If enterprises provide high compensation for employees, employees should return to the organization more actively. However, with the richness of material life and the great satisfaction of material, it is no longer sufficient to rely solely on economic benefits. The needs of employees. Compared with the social exchange relationship, in the context of economic exchange relations, employees perceive that the relationship with the organization is more of a short-term economic exchange relationship involving only materials, so employees may pay more attention to their current ability. The rewards obtained will not actively adjust themselves to the development of the organization, so the perception of employees' economic exchange relationship has a significant negative impact on organizational citizenship behavior and off-character behavior $[9,10]$. Therefore, contrary to the perception of social exchange relations, there is a negative correlation between economic exchange relationship perception and adaptive performance. Based on this, the following assumptions are made:

H2a: There is a negative correlation between economic exchange relationship perception and strain surface adaptive performance.

H2b: There is a negative correlation between economic exchange relationship perception and relationship performance.

H2c: The relationship between economic exchange relationship perception and learning surface adaptive performance is negatively correlated.

\section{The mediating role hypothesis of emotional commitment}

Domestic scholars believe that organizational commitment itself is based on two different exchange relationships: one is based on economic exchange relations, that is, employees 
establish a fixed rather than random exchange relationship between organizations in order to avoid risk selection. On the basis of this relationship, a continuous commitment is formed. Secondly, based on the social exchange relationship, employees and organizations have an emotional connection in the long-term exchange relationship. On this basis, employees will form an emotional commitment and standardization to the organization. Emotional commitment is mainly manifested in the employee's emotional dependence on the organization. This reflects whether the employee "thinks" to maintain a mental state of internal identity, and employees with high organizational commitment will try to help through their work performance. Organizational development. Emotional commitment, as an important variable in expressing employee attitudes, is often used as a mediator in research, and most studies have reached consistent conclusions that there is a significant positive correlation between emotional commitment and employee performance. In addition to job requirements, emotional commitment can also explain many of the employee's extra-character behaviors. Some scholars have also found that employees' perception of social exchange relationships also has a significant positive impact on emotional commitment. Therefore, based on the above analysis, this paper proposes the following assumptions:

H3a: Emotional commitment plays a mediating role between employee social exchange relationship perception and response performance.

H3b: Emotional commitment plays a mediating role between employees' social exchange relationship perception and relationship-oriented performance.

H3c: Emotional commitment plays a mediating role in employee social exchange relationship perception and learning face adaptation performance.

According to the above assumptions, the theoretical model of this paper is shown in Fig. 1:

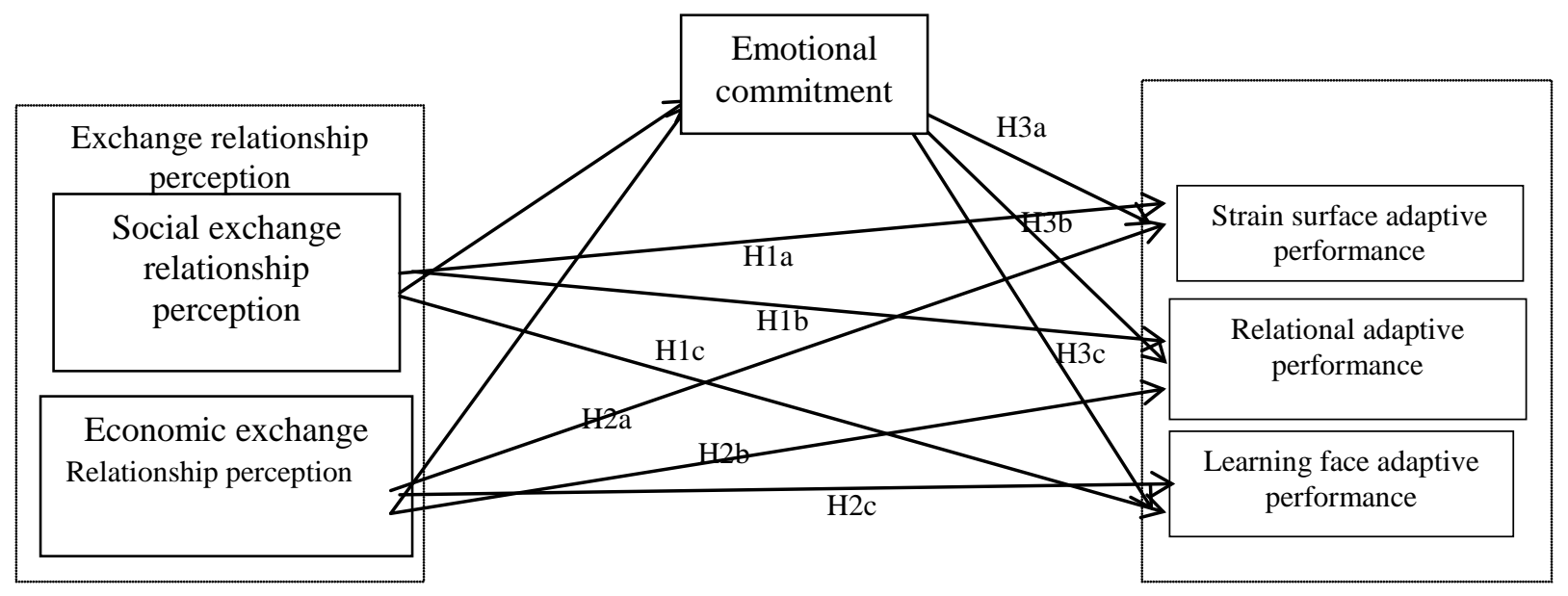

Fig. 1. Theoretical model

\section{VARIABLE SELECTION AND MEASUREMENT}

Based on the existing mature scales, this study uses the Likert 5-point scale to measure the variables involved in the theoretical model. The respondents are asked to select options based on their personal feelings and experiences in the enterprise. Among them, " 1 ” means "completely agree”, "2" means "comparative consent", " 3 " means "unsure", " 4 " means "relative disagree”, "5” means "completely disagree”, specific The measurement indicators are based on existing mature scales at home and abroad, using questionnaires for data collection and collation.

\section{A. Scale design}

\section{1) Exchange relationship perception}

The exchange relationship perception was officially proposed as a formal construct in 2009, so its research is relatively scarce. The current research draws on Shore's scale design and is translated and continually revised. Therefore, this paper also draws on this scale, and finally forms a scale for the six questions of social exchange relationship perception and economic exchange relationship perception.

\section{2) Emotional commitment}

At present, the most widely accepted measure of organizational commitment is the three-factor scale proposed by Meyer and Allen[11]. The organizational commitment is divided into emotional commitment, continuous commitment and normative commitment. The empirical verification has good reliability and validity. Therefore, this paper also draws the four questions of emotional commitment from the scale with reference to the scale developed by Meyer and Allen.

\section{3) Adaptive performance}

Zhuang Rusong[12] and other people's research divides adaptive performance into three dimensions: strain surface adaptation performance, relationship surface adaptation performance and learning surface adaptation performance. Therefore, this paper adopts adaptive performance measurement and also uses the scale of Zhuang Rusong et al. The table has undergone rigorous statistical tests and thus has good reliability and validity. The scale includes 9 adaptability 
performances, 6 adaptive performances, and 19 adaptive learning performances. According to the research needs, this paper has carried out appropriate deletions, and finally formed the 6 questions of adaptability performance of strain surface, 5 questions of adaptive performance of relationship, 4 questions of adaptive performance of learning face, and a scale of 15 questions.

\section{B. Small sample test}

In order to ensure the reliability and validity of the large sample formal questionnaire, this study first conducted a small sample pre-test, a small sample survey was completed by 60 employees, and the questionnaire was revised according to the pre-test results. The Cronbach' $\alpha$ coefficient (Cronbach, 1951) developed by the Likert scale was used to estimate the reliability of the questionnaire as a whole and the subscales. The results showed that all variables Cronbach's $\alpha>0.7$, multiquantity table Cronbach's $\alpha>0.8$, which indicates that the reliability of the questionnaire is higher, and the internal consistency between the various questions is greater.

\section{DATA COLLECTION AND PROCESSING}

\section{A. Sample selection and correlation analysis}

The questionnaire was conducted anonymously and was sampled by companies in the Beijing-Tianjin-Hebei region.
The respondents were from different industries and employed by different companies. Of the 258 questionnaires returned, only 238 were valid, and the effective rate of the questionnaire was $92.25 \%$. This study used SPSS to perform descriptive statistical analysis on the relevant data of 238 valid questionnaires, including gender, marital status, and education, working years, nature of the company, job category, job nature and employee.

The reliability test is mainly to ensure the internal consistency of the scale. It is generally necessary to analyze each dimension, each variable and the entire questionnaire. In empirical studies, Cronbach's Alpha coefficient is often used as a measure of reliability. The reliability coefficient values of all scales in the questionnaire are higher than 0.7 , so the reliability of the questionnaire is good.

This study analyzed the correlation of all variables(see TABLE I), in which A1 represents the perception of economic exchange relationship, A2 represents the perception of social exchange relationship; B represents emotional commitment; C1 represents adaptability of strain surface, $\mathrm{C} 2$ represents adaptive performance of relationship, C3 represents learning Face-toface performance, $\mathrm{C}$ indicates adaptive performance.

TABLE I. CORRELATION ANALYSIS

\begin{tabular}{|c|c|c|c|c|c|c|c|c|}
\hline & & A1 & A2 & $\mathrm{B}$ & C1 & $\mathrm{C} 2$ & C3 & $\mathrm{C}$ \\
\hline \multirow[t]{2}{*}{ A1 } & Correlation & 1 & & & & & & \\
\hline & Significant & & & & & & & \\
\hline \multirow[t]{2}{*}{ A2 } & Correlation & -.031 & 1 & & & & & \\
\hline & Significant & .632 & & & & & & \\
\hline \multirow[t]{2}{*}{$\mathrm{B}$} & Correlation & $-.244^{* *}$ & $.453^{* *}$ & 1 & & & & \\
\hline & Significant & .000 & .000 & & & & & \\
\hline \multirow[t]{2}{*}{ C1 } & Correlation & -.010 & $.312^{* *}$ & $.346^{* *}$ & 1 & & & \\
\hline & Significant & .878 & .000 & .000 & & & & \\
\hline \multirow[t]{2}{*}{$\mathrm{C} 2$} & Correlation & $-.151^{*}$ & $.296^{* *}$ & $.344^{* *}$ & $.438^{* *}$ & 1 & & \\
\hline & Significant & .020 & .000 & .000 & .000 & & & \\
\hline \multirow[t]{2}{*}{ C3 } & Correlation & $-.159^{*}$ & $.389^{* *}$ & $.378^{* *}$ & $.539^{* *}$ & $.468^{* *}$ & 1 & \\
\hline & Significant & .014 & .000 & .000 & .000 & .000 & & \\
\hline \multirow[t]{2}{*}{$\mathrm{C}$} & Correlation & $-.136^{*}$ & $.412^{* *}$ & $.441^{* *}$ & $.802^{* *}$ & $.790^{* *}$ & $.835^{* *}$ & 1 \\
\hline & Significant & .036 & .000 & .000 & .000 & .000 & .000 & \\
\hline
\end{tabular}

\section{B. Hypothesis testing and results discussion}

The results of regression are shown as TABLE II.

TABLE II. REGRESSION ANALYSIS RESULTS OF EXCHANGE RELATIONSHIP PERCEPTION AND ADAPTIVE PERFORMANCE

\begin{tabular}{|c|c|c|c|c|c|c|}
\hline & \multicolumn{2}{|c|}{$\begin{array}{c}\text { Strain surface adaptive } \\
\text { performance }\end{array}$} & \multicolumn{2}{|c|}{$\begin{array}{l}\text { Relational adaptive } \\
\text { performance }\end{array}$} & \multicolumn{2}{|c|}{$\begin{array}{c}\text { Learning face adaptive } \\
\text { performance }\end{array}$} \\
\hline & Model one & Model two & Model one & Model two & Model one & Model two \\
\hline (constant) & $2.548^{* * *}$ & $1.772^{* * *}$ & $2.460^{* * *}$ & $1.981^{* * *}$ & $2.711^{* * *}$ & $1.942^{* * *}$ \\
\hline gender & -0.088 & -0.030 & $-0.273^{* * *}$ & $-0.216^{* * *}$ & $-0.163^{*}$ & -0.082 \\
\hline marital status & 0.002 & -0.022 & 0.039 & -0.016 & -0.145 & $-0.176^{*}$ \\
\hline Education & 0.102 & $0107^{*}$ & 0.061 & 0.072 & 0.085 & 0.099 \\
\hline Nature of business & $-0.057^{*}$ & -0.047 & 0.015 & 0.020 & -0.053 & -0.044 \\
\hline Working years & -0.004 & -0.022 & 0.001 & -0.023 & 0.016 & -0.016 \\
\hline Position & $-0.114^{*}$ & -0.081 & -0.088 & -0.050 & $-0.115^{*}$ & -0.062 \\
\hline Post nature & 0.040 & $0.050^{*}$ & 0.11 & 0.018 & 0.028 & 0.038 \\
\hline Employee type & -0.060 & -0.043 & -0.056 & -0.036 & -0.117 & -0.189 \\
\hline
\end{tabular}


Cont.to TABLE II.

\begin{tabular}{|c|c|c|c|c|c|c|}
\hline $\begin{array}{l}\text { Independent variable: economic exchange relationship } \\
\text { perception }\end{array}$ & & -0.003 & & $-0.094^{*}$ & & $-0.107^{*}$ \\
\hline $\begin{array}{l}\text { Independent variable: social exchange relationship } \\
\text { perception }\end{array}$ & & $0.275^{* * *}$ & & $0.268^{* * *}$ & & $0.383^{* * *}$ \\
\hline F value & $2.268^{*}$ & $4.161^{* * *}$ & $2.408^{*}$ & $4.407^{* * *}$ & $2.010^{*}$ & $6.282^{* * *}$ \\
\hline R side & 0.073 & 0.155 & 0.078 & 0.163 & 0.066 & 0.217 \\
\hline Adjust the R side & 0.041 & 0.118 & 0.045 & 0.126 & 0.033 & 0.182 \\
\hline D-W value & 2.038 & 2.038 & 1.740 & 1.740 & 2.210 & 2.210 \\
\hline
\end{tabular}

\section{Results discussion}

From the results of the above table, we can see that the three dimensions of social exchange relationship perception and adaptive performance have significant positive predictive effects, namely, social exchange relationship perception and strain surface adaptive performance, relational adaptive performance and learning face adaptability performance is positive. Therefore, it is assumed that H1a, H1b, and H1c are all established. However, the perception of economic exchange relationship is only related to the relationship between adaptive performance and learning surface adaptive performance in the three dimensions of adaptive performance, and it is a negative effect, so it is assumed that H2b and H2c are established.

The three dimensions of social exchange relationship perception and adaptive performance have a significant positive impact, because if employees perceive that they and the company are not only materially connected, but also emotionally connected, then the company will There will be a stronger sense of belonging, and we will work hard to improve our ability in all aspects. At the same time, we will work hard to make good relationships with other employees in the organization, adapt to different working atmospheres, and actively learn and work-related knowledge to better reward.

Employees' perception of economic exchange relationship has a significant negative impact on adaptive performance in addition to the other two dimensions of adaptability performance. This is because employees believe that they are only a short-term material exchange with the company, so they will not care. The future of the company will not take the cooperation with other employees seriously, let alone study hard and work-related knowledge to serve the enterprise. However, the relationship between employee economic exchange relationship perception and strain surface adaptability performance is not significant. This may be because the adaptability performance of the strain surface is the ability of employees to respond to emergencies, which is more related to the quality of the individual. And in the economic exchange relationship, usually only a short-term exchange, so the employee's adaptability performance will not be reflected.

In order to verify the mediating role of emotional commitment in the three dimensions of social exchange relationship perception and adaptive performance, a three-step regression is needed. The first step is to test the total effect, that is, the impact of social exchange relationship perception on the adaptive performance of the face. The second step is to test the impact of social exchange relationship perception on emotional commitment. The third step is to use social exchange relationship perception and emotional commitment as independent variables, and the three dimensions of adaptive performance are regression of dependent variables. The test results are as follows (see TABLE III):

TABLE III. MEDIATION TEST

\begin{tabular}{|c|c|c|c|c|}
\hline \multicolumn{2}{|r|}{ Model } & Strain surface adaptive performance & Relational adaptive performance & Learning face adaptive performance \\
\hline \multirow{2}{*}{1} & (constant) & $1.772^{* * *}$ & $1.981^{* * *}$ & $1.942^{* * *}$ \\
\hline & Social exchange relationship perception & $0.275^{* * *}$ & $0.268^{* * *}$ & $0.383^{* * *}$ \\
\hline \multirow{2}{*}{2} & (constant) & $1.371^{* * *}$ & $1.371^{* * *}$ & $1.371^{* * *}$ \\
\hline & Social exchange relationship perception & $.47^{* * *}$ & $.47^{* * *}$ & $.47^{* * *}$ \\
\hline \multirow{3}{*}{3} & (constant) & $1.272^{* * *}$ & $1.038^{* * *}$ & $.642^{* * *}$ \\
\hline & Social exchange relationship perception & $.181^{* *}$ & $.178^{* *}$ & $.285^{* * *}$ \\
\hline & Emotional commitment & $.228^{* * *}$ & $.253^{* * *}$ & $.249^{* * *}$ \\
\hline
\end{tabular}

From the coefficient test in the above table, we can find that all the coefficients are significant. Therefore, it can be proved that emotional commitment plays a mediating role between the three dimensions of social exchange relationship perception and adaptive performance, and plays a partial intermediary role. Therefore, it is assumed that $\mathrm{H3a}, \mathrm{H} 3 \mathrm{~b}$, and $\mathrm{H3c}$ are established.

This result shows that the perception of social exchange relationship can directly affect the three different facets of employee's adaptive performance, and on the other hand, it can have an indirect effect through the intermediary role of emotional commitment. This may be because employees who perceive the exchange relationship between themselves and the organization is a social exchange, then employees will naturally have more emotional input to the organization, and then change their behavior to adapt to the enterprise, and strive to improve Their own ability to help companies face environmental uncertainty, so emotional commitment will play a partial intermediary role in social exchange relationship perception and adaptive performance. 


\section{CONCLUSION AND OUTLOOK}

\section{A. Research Conclusion}

1) To build positive human resource management practices to enhance employees' perception of social exchange relationship.

This study shows that there is a significant positive relationship between employees' social exchange relationship perception and adaptive performance. In fact, according to the theory of social exchange, the implementation process of human resource management practice is itself an exchange process between employees and organizations[13]. Therefore, the incentives provided by the organization for employees should not only include some material incentives such as salary and benefits, but also strengthen emotional communication with employees. For example, we can hold regular communication meetings with employees, conduct personal career counseling for employees, etc., so that employees perceive the organization. The concern, and thus the perception of social exchange relations with the organization.

2) To design a performance evaluation system suitable for enterprise development according to the specific conditions of the enterprise.

For organizational performance, task performance, context performance, and adaptive performance each have their own unique value. However, we find that the antecedent variables affecting the performance of these three types of work are different, so companies should focus on the performance of these three types of work according to the actual situation. If the organization is in a rapidly changing environment, or in the period of entrepreneurship and change, it should focus on the evaluation of employee's adaptive performance in performance evaluation; if it is in a relatively stable environment, then perhaps more attention should be paid to the task. Performance or peripheral performance. But in any case, if employees have high adaptive performance, it will promote the long-term development of the company.

\section{B. Future prospects}

This study has drawn some valuable conclusions, which have certain contributions to the research on employee exchange relationship perception and adaptive performance. However, due to the influence of subjective and objective factors such as knowledge level and time, there are still some shortcomings in the future. The study can be improved from the following points. a) Using a more scientific questionnaire recovery method, on the one hand, it is necessary to expand the scope of the survey to increase the number of questionnaires to be collected, and to improve the representativeness of the sample. On the other hand, it is necessary to comprehensively measure the employee's working years and the balance of age, and strengthen the quality control of the survey. Improve the effective recovery rate of the questionnaire. b) Expand the research on the perception of employees' social exchange relationship. At present, there is relatively little research on the perception of employees' social exchange relationship, so the connotation and measurement have not yet formed a unified understanding, which needs further study. c) Further strengthen the research on the impact mechanism of adaptive performance. Although the conclusions of this paper point out the mechanism of social exchange relationship perception and its interaction mechanism, the relationship between the two may be realized by other important variables, so further research can be carried out in future research.

\section{REFERENCES}

[1] Neal A F, Hesketh B. Technology and performance[J]. 1999:21-55.

[2] Iigen, Daniel R., Ed.Pulakos, Elaine D., Ed. The Changing Nature of Performance: Implications for Staffing, Motivation, and Development. Frontiers of Industrial and Organizational Psychology.[M]. Jossey-Bass Publishers, 1999.

[3] Pulakos E D, Arad S, Donovan M A, et al. Running Head: ADAPTIVE PERFORMANCE Adaptability in the Workplace: Development of a Taxonomy of Adaptive Performance[J]. 2000, 85(4):612-624.

[4] Griffin M A, Neal A, Parker S K. A New Model of Work Role Performance: Positive Behavior in Uncertain and Interdependen Contexts[J]. Academy of Management Journal, 2007, 50(2):327-347.

[5] Elaine D. Pulakos, Neal Schmitt, David W. Dorsey, et al. Predicting Adaptive Performance: Further Tests of a, Model of Adaptability[J]. Human Performance, 2002, 15(4): 299-323.

[6] Griffin, Ricky W. Fundamentals Of Management: Core Concepts And Applications[J]. 2003.

[7] Shoss M K, Witt L A, Vera D. When does adaptive performance lead to higher task performance?[J]. Journal of Organizational Behavior, 2012, 33(7):910-924.

[8] Dandan Huo. The Impact of Exchange Relationship Perception on Employees' Adaptive Performance: The Mediating Role of Organizational Commitment [D]. Tianjin University of Finance and Economics, 2017. (In Chinese)

[9] Lynda Jiwen Song,Anne S. Tsui,Kenneth S. Law.Unpacking Employee Responses to Organizational Exchange Mechanisms:The Role of Social and Economic Exchange Perceptions.Journal of Management,Vol. 35 No. 1,February 2009 56-93.

[10] Yanhan Zhu. Study on the mechanism of employee exchange relationship perception on individual behavior [D]. Southwestern University of Finance and Economics, 2011. (In Chinese)

[11] Allen N J, Meyer J P. Organizational commitment: Evidence of career stage effect?[J]. Journal of Business Research, 1993, 26(1):49-61.

[12] Rusong Zhuang. The development of adaptive performance scale and its relationship with goal-oriented and forward-looking personality [D] University of Political Science, 2009. (In Chinese)

[13] Hongying Li. A cross-level study on the impact mechanism of strategic human resource management on employee performance and contingency factors [D]. Jilin University, 2017.(In Chinese) 